\title{
Exploring Learning Strategies of Nursing Students at Hue University of Medicine and Pharmacy, Vietnam
}

\author{
Nguyen Thi Anh Phuong, Ho Thi Thuy Trang, Ton Nu Minh Duc, \\ Tran Thi Nguyet, Tran Thi Hang, Nguyen Thi Thu Thao, \\ Nguyen Vu Quoc Huy
}

Hue University of Medicine and Pharmacy, Hue University, Hue city, Vietnam

Background: Application of appropriate teaching and learning strategies is a necessary way of influencing student learning outcomes. The purpose of this study was to explore students' views, perceptions and the effects of these on different teaching and learning approaches.

Methods: Twenty one nursing students who were exposed to different teaching strategies were selected as a purposive sample for this study. Qualitative analysis of feedback from six individual interviews and two focus groups encompass a rich data set to inform nurse educators about student perceptions regarding impact of teaching approaches on their learning outcomes.

Results: Participants indicated advantages and disadvantages of each of the teaching strategies and recommended suggestions for improving learning outcomes. The findings also described how a student's preferred learning strategy impacted on learning outcomes when criteria for surface, deep and strategic approaches were taken into consideration.Conclusions: This research provides evidence for educators on the effects of innovative teaching and learning strategies in nursing education. It also provides preliminary feedback on the extent of achievements on the movement towards national reforms in higher education.

Keywords: Blended learning strategies; PBL in nursing; Educational reform in Vietnam

\section{INTRODUCTION}

Nowadays, Vietnam is pursuing greater levels of international integration and renovation in all fields, including education and training. As it is considered a dynamic country with a young population, Vietnam has seen a significant increase in the number of higher education students compared with the past 20 years. Renovation of higher education systems and processes is an urgent requirement to improve the quality of teaching and learning in Universities (Resolution 29/TW-Vietnamese Communist Party, 2013). To achieve this goal, a lot of policies, strategies and action plans were set up and implemented in the universities with oversight from MOET (Ministry of Education and Training).

Some achievements include developing and perfecting formal documents to improve the quality of education management outcomes; budget increases at the national level for higher education; rapid increases in the number of the public and private universities and the growth in number and quality of teaching staff (MOET, 2018). However, there are still many challenges and limitations. Within survey findings, commentary on Vietnamese teaching and learning methods was as follows:

The method of teaching is not effective, present only and less use of active learning skills. Therefore, there are less interactions between students and teachers inside and outside the

\author{
Received: September 28, 2020 \\ Revised: October 28, 2020 \\ Accepted: October 30, 2020 \\ Corresponding author: \\ Nguyen Thi Anh Phuong, MD, PhD \\ Dean, Facutlty of International \\ Education Hue University of Medicine \\ and Pharmacy, Hue University Hue \\ city, Vietnam, 530000 \\ Tel: +84.947641177 \\ Fax: +84.234.3826269 \\ Email: puong.nta@huemed-univedu.vn
}

(C) Copyright 2020 International Society for Problem-Based Learning

(c) This is an Open Access article distributed under the terms of the Creative Commons Attribution Non-Commercial License (http://creativecommons.org/licenses/ by-nc/4.0/) which permits unrestricted non-commercial use, distribution, and reproduction in any medium, provided the original work is properly cited. 
classroom; too much emphasis on memorizing knowledge without relying on high-level conceptual or academic learning such as analysis and synthesis, as consequence in superficial learning instead of active learning; students learn passively (Ngo, 2010);

...to date, no Vietnamese universities are ranked in the world's top 1,000 universities (based on well-known world university rankings). The regulatory environment is highly bureaucratic and centralized through the Ministry of Education and Training (MOET), which has authority over education, including higher education (Temmerman, 2019).

Hence, innovation to transform higher education in Vietnam is essential to achieve education consistent with countries in the region and across the world. This demands comprehensive procedures including: curriculum reform, accreditation, teacher quality and alternative ways of teaching (Temmerman, 2019). As a consumer of education, the student should be offered ways to change their learning process to adapt to innovation. Currently, many universities in Vietnam have changed and applied more active teaching methods in education, with the aim of achieving student-centered approaches to learning, enhancing creativity and encouraging active participation in learning processes, applying knowledge in practice and being able to solve the real-life problems. Specifically, for the medical and health professions, after graduation, professionals must be able to work and deal well with matters related to human health, thus educational renovation that closely relates to dealing with 'reality' is necessary. In recent years, Hue University of Medicine and Pharmacy (Hue UMP) has applied new methods of teaching and learning in parallel with traditional teaching methods in medical education such as case-study, E-learning, U-learning, problem-based learning (PBL), team based-learning (TBL), and involvement with simulation for learning. As a result, there are many positive changes in teaching and learning processes in Hue UMP (Nguyen et al. 2017).

However, the application of such new methods will affect the student's learning strategies. Many students experienced some "embarrassment with the new method", other students found it "difficult to find reference materials" and reported that "reasonable time allocation to group-work is also an obstacle". In addition, students feel exhausted from a busy study workload that was a consequence of the method that demanded more active learning; students sometimes feel very pressured. Students complained that they spend a lot of time on one subject and that affects other subjects (Tran et al. 2017). Devine and Meagher (1989), decades ago, acknowledged there were many factors which contribute to students' success. The most important were to know how to learn, manage time, read and listen effectively, take effective notes, understand and remember. Learning strate- gies are "behaviours of a learner that are intended to influence how the learner processes information" (Mayer, R. 1988). It is evident from a number of other studies that study strategies have a positive effect on achievement of goals (Marzano, Pickering \& Pollock, 2001; Heath, Ellen \&Kaira, 2009).

Therefore, understanding student's learning strategies when applying more active teaching methods is necessary for teachers and students to find the optimal approaches in order to improve student's academic experiences. In addition, this process improvement contributes to maintenance of quality in teaching and learning within the Hue UMP. The purposes of study were to determine nursing students' perception on different teaching and learning strategies; explore student's learning approaches related to various teaching strategies; and describe instructional strategies that promote optimal student learning outcomes.

\section{METHODS}

A qualitative descriptive approach was used for this research, that aimed to explore nursing student perspectives on their learning experiences. Six in-depth interviews and two focus groups (6-7 students/group) were conducted using semi-structured interviews with open-ended questions to collect subjective data sets. Observations of learning events and field notes and memos supported data collection and analysis.

\section{Research setting}

The research setting in the Hue University of Medicine and Pharmacy in Vietnam provides a variety of nursing programs for both undergraduate and postgraduate (masters) levels. Several teaching and learning approaches involved in nursing education aimed to promote deep learning.

\section{Research participants}

The study participants were 21 students receiving different teaching approaches ranging from online to 'in class' strategies including lecture-based, problem-based, U-learning and E-learning within an undergraduate baccalaureate nursing program. A purposive sampling method was used to recruit the participants.

\section{Data collection process}

Faculty members developed and implemented several teaching strategies into each nursing module. Following the educational activity, separate evaluation processes were used to assess the effectiveness of the teaching approaches. The researcher conducted and audio-recorded six in-depth interviews and two separate focus group discussions to explore views on experiences of stu- 
dents regarding their learning experience. In addition, observations proposed from feedback during focus groups, allowed for further investigation of the responses of students when exposed to the learning setting. The observer recorded students' activities and conversations for analysis. Field notes and memos also contributed to data analysis. Semi structure interviews and focus groups were guided by prompts such as, "Please tell me your experience/ views with teaching and learning strategies used in the nursing educational program"; "Please share your opinions about an effective teaching strategy and your learning process"; "Please tell me about the suggestions for improving effectiveness of teaching and learning strategy".

\section{Data analysis}

The recordings of the focus groups were transcribed after the end of the interview sessions. Qualitative content analysis aimed for rich and deep information. The investigator read and reread all data sets. Emerging themes were systematically recorded with data arranged and collated according to categories. The data from observation, field notes and memos were included throughout the analysis. The Atlas.ti 8.0 program was applied for analysis of data on teaching approaches used.

\section{Ethical Issues}

Permission for the conduct of the research was received from Hue University of Medicine and Pharmacy, in Vietnam. Throughout the study, ethical principles were applied - the purpose of the study was explained to all the participants and informed consent was obtained for each interview and voice recording and observations. The participants were assured of the confidentiality of the data. In addition, the recorded interviews were kept in a safe place, only accessible by the researchers.

\section{Findings}

1. Exploration of perceptions of nursing students toward different teaching-learning methods

Findings indicate students' perceptions are divided into advantages and limitations. Results showed students' perceptions on advantageous aspects of five teaching-learning methods. The benefits of the traditional lecture-based method used for 'fixed resource sessions', were seen as provision of consistent and detailed knowledge, material that was easy to understand and convenient to review, and appropriateness to the study schedule.

"... all knowledge is available in the text-book; I can just look back whenever I need. Besides, through lectures, I can also learn (from the) experience (of) my teachers, It's easier to learn and to understand than reading books or searching information myself..."

"... with a busy study schedule, the traditional method seems to be more convenient, we spend less time preparing at home... just need to listen to lecture in class and try to remember ..."

"... for the basic subjects, I think traditional teaching method is very suitable because those subject maintain specific content, the definitions and principles are fixed and brief... listening to lectures teaches, (shows how to) analyze problems and gives examples, students will easily understand..."

Through activities within methods such as PBL, E-learning and U-learning, students reported feeling that these were more convenient, they could be more proactive and creative. They valued visual content, activities helped them improve not only nursing skills and knowledge, but also non-technical skills including communication, leadership, team-work, decision-making, and situation-awareness skills. The participants suggested advantages of PBL methods involved proactivity; these were positive and creative methods leading to deeper learning, increased interaction, increased independence, increased ability to apply learning in clinical practice, develop non-technical skills, and add more knowledge taken out of textbooks.

"... with a given case study, students will actively learn about knowledge, when discussing and exchanging between groups, they should have complete knowledge (to provide) for each other between groups...”

“... making reports, students will read more documents on assigned issues...",

"... students should also interact (report from other groups), (be) open-minded and receive new things, some information needs teachers to correct and analyze, ones (that are) are beneficial should be applied",

"... when presenting a report, helping me feel more confident, when listening to other groups presenting, if I don't understand, I will confidently ask my friends so I can improve my questioning skills..."

"... my communication skills also increased significantly, I confidently give my opinions and make it clear, in group discussion we usually (have) arguments or conflicts - I know how to calmly resolve (these). And at presentation, I can give my feedback and open-mindedly receive feedbacks from my friends...".

In addition, most participants mentioned the convenience of the approach, stimulating learning processes and improving learning efficiency. Improving independence and being proactive were positive outcomes from e-learning, for example

"... study at home, I can arrange to study at my leisure time, I can study early because the teachers have assigned the lesson first ..."

"...because the phone can be used, students often read it, students have to go to school less often...”, 
“... videos about techniques, watching videos I know how to do, easier to remember... than reading books... when reading books, I could not imagine, but watching the video I will know how to do this step by step",

"... students are more proactive, increase their independence and learn for themselves ..." For the U-learning approach, the participants again recognized the convenience of the approach, it was visual and easy to understand, it increased their ability to apply ideas in clinical practice, and it was convenient and offered various styles in examinations.

"...everyone has a smartphone, they can connect to the internet and download documents and then learn anywhere, anytime ...",

"...I can see how the symptoms, the signs like, accessible by images, videos, so I can visualize it more easily",

"... while studying, students can compare to real clinical situations, have videos on clinical situations, so the ability to apply in clinical practice is higher ...",

"... I like the way this method works, how to do the exercises on the tablet, without using paper and pen, (teachers) can apply many types to make questions, pictures, videos, richer topic types and know the score immediately after the exam ..."

The results in Table 1 illustrated the student's perceptions about disadvantages related to receiving different teaching strategies. The lecture based-approach posed limitations on long-term memorization and expansion of knowledge, was less focused on skills development and difficult to apply to clinical practice. It was not learner-centered, inactive and less interactive and inferior and boring.

"I think the traditional method is not good, ineffective because students only listen to teachers impart knowledge, not actively searching for knowledge to enrich their learning content".

"I rate the traditional method at an average level, usually after finishing the exam, I will not remember so much, only remember temporarily but not for long",

"... the traditional method is not student-centered, in the process of learning, students mainly listen to the lectures, sometimes, teachers combine with power point slides to teach",

"Actually, the interaction and interaction between students and lecturers is very rare, so many students may not understand some problems but are afraid to raise their opinions, hesitate to talk to the lectur-

Table 1. Students' perceptions of different teaching-learning strategies

\begin{tabular}{|c|c|c|}
\hline \multirow[t]{2}{*}{ Instructional strategy } & \multicolumn{2}{|c|}{ Students' perceptions of different teaching-learning strategies } \\
\hline & Advantage & Disadvantage \\
\hline & $\begin{array}{l}\text {-Provide consistent and detailed knowledge; easy to } \\
\text { understand and convenient to review }\end{array}$ & $\begin{array}{l}\text {-Limitations on long-term memorization and expand knowl- } \\
\text { edge }\end{array}$ \\
\hline \multirow[t]{5}{*}{ Traditional learning method } & -Providing appropriate study schedule & $\begin{array}{l}\text {-Less focus on skills development and difficult to apply to } \\
\text { clinical practice }\end{array}$ \\
\hline & -Leading good score in final examination & -Non-learner-centered \\
\hline & & -Inactive and less interactive. \\
\hline & & -Inferior and boring. \\
\hline & & $\begin{array}{l}\text {-Difficult to control learning effectiveness due to depen- } \\
\text { dence on external factors: number of students, environ- } \\
\text { ment, capacity and culture of teachers }\end{array}$ \\
\hline \multirow[t]{6}{*}{ Problem based learning } & -Proactive, positive and creative method & -Takes a lot of time \\
\hline & -Deep learning approach & -Difficult to arrange time for group work \\
\hline & -Increases interaction & -Uncertainty of information from internet \\
\hline & $\begin{array}{l}\text {-Increases independence } \\
\text {-Increases the ability to apply in clinical practice }\end{array}$ & $\begin{array}{l}\text {-Knowledge acquistion limited of the whole lesson related to } \\
\text { focusing mostly on dealing with their own group's problem } \\
\text { solving assignment }\end{array}$ \\
\hline & -Add more knowledge out of textbooks & $\begin{array}{l}\text {-Difficult to understand the lesson related to limitation on } \\
\text { student's presentation skills and lack of concentration }\end{array}$ \\
\hline & & $\begin{array}{l}\text {-Difficulties related to lack of computers and limitations in } \\
\text { Power Point making skills }\end{array}$ \\
\hline \multirow[t]{3}{*}{ E-learning } & -Convenience of approach & -Limit the fairness in the examination \\
\hline & -Stimulate learning process and improve learning efficiency & -Depends on internet quality \\
\hline & -Improves independence and proactivity & \\
\hline \multirow[t]{4}{*}{ U- learning } & -Convenience of approach & -Depends on device quality \\
\hline & -Visual and easy to understand & \\
\hline & -Increases the ability to apply in clinical practice & \\
\hline & -Convenient and various styles in examination & \\
\hline
\end{tabular}


Table 2. Explore students' learning approaches related to various teaching strategies

\begin{tabular}{|c|c|c|c|c|}
\hline Method & Surface approach & Deep approach & Strategic approach & Long-term learning outcomes \\
\hline \multirow[t]{6}{*}{$\begin{array}{l}\text { Traditional learning } \\
\text { method }\end{array}$} & Textbook-based learning & $\begin{array}{l}\text { Relating and organizing ideas } \\
\text { and concepts }\end{array}$ & $\begin{array}{l}\text { Self-testing/predict exam } \\
\text { questions }\end{array}$ & $\begin{array}{l}\text { Contributing good academic } \\
\text { achievement }\end{array}$ \\
\hline & Passive learner & Seeking meaning & Self-motivation & $\begin{array}{l}\text { Efforts towards student's life and } \\
\text { career }\end{array}$ \\
\hline & Encourage self-learning & $\begin{array}{l}\text { Seeking appropriate material/ } \\
\text { resources }\end{array}$ & Seek help & \\
\hline & $\begin{array}{l}\text { Effective reading and listen- } \\
\text { ing skills }\end{array}$ & Relates theory to practice & Time and effort management & \\
\hline & Syllabus-bound & $\begin{array}{l}\text { Self-directed learning moti- } \\
\text { vation }\end{array}$ & & \\
\hline & & self-questioning strategy & & \\
\hline \multirow{8}{*}{$\begin{array}{l}\text { Problem-based learning } \\
\text { method }\end{array}$} & Passive learners & Actively learners & Peer learning & \\
\hline & Unthinking acceptance & Integrate theory and practice & Time management & \\
\hline & & Actively interact & Self-directed learning & \\
\hline & & $\begin{array}{l}\text { Self-motivated/Motivated by } \\
\text { interest }\end{array}$ & Group work & \\
\hline & & Systematic Memorization & Self-testing & \\
\hline & & Decision-making & & \\
\hline & & Problem-solving skills & & \\
\hline & & Critical thinking & & \\
\hline \multirow{4}{*}{$\begin{array}{l}\text { E-learning, U-learning } \\
\text { method }\end{array}$} & Encourage self-learning & Seeking meaning & Time and effort management & \\
\hline & & Motivated by interest & Self-testing & \\
\hline & & $\begin{array}{l}\text { Seeking appropriate material/ } \\
\text { sources }\end{array}$ & & \\
\hline & & $\begin{array}{l}\text { Relating and organizing main } \\
\text { ideas and concepts }\end{array}$ & & \\
\hline
\end{tabular}

ers, hesitate to raise (issues) in front of the class"

The participants reflected on disadvantages of PBL learning methods, including perceptions about time, difficulties arranging time for group work, uncertainty about information found on the internet, knowledge acquisition for whole lessons versus mostly dealing with their own group's problem solving assignment, difficulties related to limitations on student's presentation skills and lack of concentration, difficulties related to lack of computers and limitations in Power Point skills. For online strategies, fairness in examination related to internet and device quality.

“... with PBL methods, it takes a lot of time to search for information, read and understand materials, then discuss in group to solve the problem, finally making PowerPoint presentation also takes too much time...",

"When doing assigned homework, some students just copy from books or internet into the presentation without understanding, then when other group members ask, they do not know and cannot answer",

"When we search for information on the internet, there are many sources so we don't know which one is reliable",

"For PBL, I only focus on my group, the knowledge given by other groups seems hard to understand because we don't have time to learn information of other group's part, so it's very difficult to absorb",

"I like to study on a tablet, but sometimes the server has problems, it always takes about 30 minutes to fix, to check if it's stable".

2. Exploration of student's learning approaches related to various teaching strategies

Based on guidelines in Newble and Entwistle's model (1986), the researchers reflected on the data and how different teaching strategies effect student's surface, deep and strategic learning approaches.

Within a traditional teaching-learning method, there are five elements within a surface learning approach: It is syllabus bound, textbook-based, involves passive learners, encouragement of individual learning, and promotion of effective reading and listening skills. Students perceived that traditional methods were still valuable, especially for basic nursing subjects. In this basic knowl- 


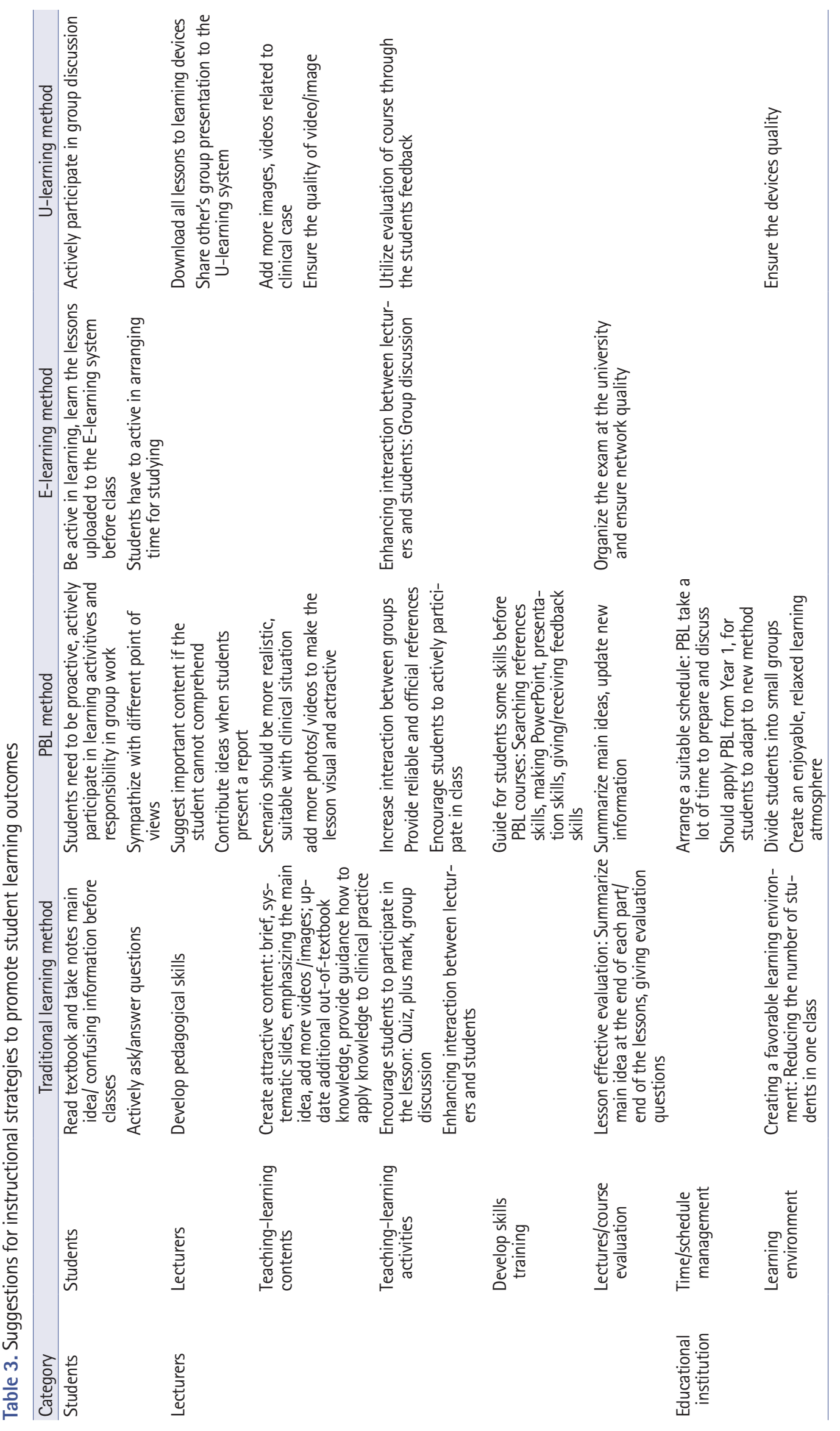


edge block, students needed a wide approach to knowledge acquisition, an ability to grasp the general knowledge and systematically connect the knowledge before focusing on the depth of the knowledge in specialized blocks. Therefore, given that they were getting knowledge from reliable resources such as textbooks, teachers' lectures were considered an effective resource. While promoting students effective reading and listening, it encouraged individuals to work on their own. However, traditional methods also bring negative effects to learners as familiarity with passive learning methods limits the intention to expand personal knowledge acquisition and thus become more autonomous learners.

"I think students should learn based on textbook, if they want to get high academic achievement, just repeat reading textbook as much as possible"

"In class, I focus on listening to lectures, underline main ideas in textbook, but I usually do not review until before examination, when I try to learn, I cannot remember anything, like reading them at the first time"

"I mostly self-study, I try to arrange study schedules to be appropriate for subjects. Before class, I read briefly lesson to grasp the main ideas,so when listening to lectures, it's easier to catch the lesson"

However, the following respondent makes a critical point:"After finishing examinations, I mostly forget all knowledge I have been studying".

On the other hand, for students, no matter what method they are offered, they will try to find the best way to achieve the specified learning outcomes. Therefore, the deeper approach to learning is still used as an effective way to understand, link and use knowledge as needed. Qualitative analysis results showed six sub-categories related to deeper approaches:

Relating and organizing ideas and concepts, seeking meaning, Seeking appropriate material/resources, Relating theory to practice, Self-directed learning motivation and a Self-questioning strategy.

"I will note the main content of the lesson systematically on the note paper according to colors and stick it on the wall in each specific area, so I just need to look at each color area to remember lessons, it's a very effective and time-saving way to study",

"... when the teacher imparts knowledge, I try to take notes, if there is anything I don't understand, I will find more external materials to better understand or discuss with classmates",

"... when I read the lesson in textbook, I do not skim it, I read carefully to understand, focus on memorizing and learn by heart, then I search on You-tube to find and listen to related lectures. If I still do not understand, I will ask my friends or teachers",

"... combine clinical and theoretical study will help students understand more because there are still many clinical cases that are not ex- actly same (consistent with) with theory... find clinical cases which (are) described in textbook and because she has read the book already, she can easily find out the symptoms and compare those reality's signs to books' content",

"When reading a textbook, I usually read carefully and continuously ask myself the question "Why?", so it makes me remember lessons longer"

"... with the subject that I like, I will study more, also useful knowledge subjects, related to my health, my family health, I'm also more interested and motivated"

One response captured the value of an engaging teacher to encourage students to be engaged with the learning resource "If the teacher gives lectures attractively, I will listen attentively and write down the main ideas, but with boring lectures, I usually focus less on listening".

Within a traditional method, students applied strategies such as: Self-testing/predicting exam questions, Self-motivation, Seeking help and Time and effort management. According to participants, learning is a process that requires learners to have a clear goal and effectively manage time and effort, moving toward achievement. In this process, seeking appropriate help and maintaining motivation can also contribute to success. Also, proper orientation and practicing the exam questions can help students show results indicative of high academic performance around demonstration of knowledge acquisition. Retention of that knowledge might be short-term.

"To prepare for the in-coming examination, I usually do available exam questions paper and find out the form of these questions, which guides me on how to study to get high achievement"

"I usually study one month before the incoming examination, I make detailed plans using suitable time and effort, then I will read textbooks, find more information online, and do available exam papers"

"At the beginning of each semester, I will ask my seniors about their experience on how to study, which subjects are easy, which subjects are difficult, then arrange time and effort to study...”.

Regarding PBL methods, findings showed that the surface approach has 2 sub-categories: Passive learners and unthinking acceptance. According to passive learners, they only listen to lectures and do not pay attention to the presentation of other groups; they do not review lessons either.

“... I only focus on my group's presentation, often overlook the other groups' presentation...”;

"Participants described the unthinking acceptance as including copying the content of the lesson to present and copying information from the internet but have not read it all",

"... I copied the content in the book to make a report, but after 
complete it, I did not understand...",

"... I copied the information from internet to make a report, but I didn't read it all..."

Findings revealed some of the sub-categories consistent with the deeper approach: Active learners, theory and practice integration, active interactions, self-motivated/motivated by interest, systematic memorization, decision-making, problem-solving skills, critical thinking.

For active learning, students want to improve knowledge and update information regularly; complete all assigned tasks and submit them on time; grasp knowledge to understand given problems; read the report of other groups posted on the available system; actively explore further; display self-learning; asking classmate/tutor about problems that they do not understand.

"... Each person needs to cultivate knowledge by themselves, in order to participate effectively in group discussion, do not be passive...",

"... In order to study well at PBL, I think that I should study for myself, read and learn more knowledge, not just passively listening to teachers..."

"For theory and practice integration, students think they have to apply theory to clinical practice; grasp clinical knowledge and practice more clinical skills",

"... I think we should combine clinical and theoretical study. Because there are many clinical cases that theories do not have, so students can learn more knowledge...",

"... In my opinion, students should go to practice more to know the real symptoms and how to handle them. It will be easier to apply and handle the situations in the lesson...",

Participants described active interactions consisting of giving questions/comments to others in the group or tutors: "... In class, I ask teachers and other members when I do not understand the problems"; or by interacting with other groups and question when needed"... Listen to other group's presentations and make questions when we do not understand...".

For Self-motivated/Motivated by interest, students showed interest in role play activities "... Combining study and play roles helps to memorize lessons better... ". Creating a fun learning atmosphere and trying to answer other group's questions"... will help everyone (learn) more actively...".

Some students described Systematic Memorization as writing down the main ideas of lesson, then synthesizing these to learn more; reviewing carefully the report they have presented. Where confusing questions needed answers "... in class, I also took notes of confusing problems that were answered...”.

For problem-solving skills, decision-making and critical thinking, participants described researcher enquiry processes -answering the question themselves or discussing these with team mem- bers to help make decisions and find the solutions for problems/ situations/questions given by the tutor.

"... I will base (this) on the problem/situation, the questions that are asked by lecturers, then I will find out, follow this case content, answer the questions by myself, make a statement...".

Regarding E- learning and U-learning methods, students' reports on use of these approaches were quite similar to those for traditional methods. Students here however, were also engaging in self-learning, a surface strategy: Seeking meaning, being motivated by interest, seeking appropriate materials/sources, relating and organizing the main ideas and concepts thus moving towards deeper learning and being strategic with time and effort management and self-testing.

In addition, the participants responded to those teaching approaches that lead to long term learning outcomes including improving self-motivation, contributing to good academic achievement, and effort to improve student's later life and career.

"I want to get a very good degree at graduate level, and intend to get a job at an international hospital. Therefore, I set goals, make detail plan, and try my best to achieve..."(Table 2)

\section{Describe suggestions for instructional strategies to promote student learning outcomes}

Students' reporting revealed three major categories: Feedback about their experiences, the lecturers and the educational institution in relation to optimal improvements in teaching and learning strategies when applying new active learning methods. The lecturer category involved feedback on teaching-learning content; teaching-learning activities; developing skills training; and lecturer/course evaluation as well. The educational institution category was focused on time/schedule management and learning environment.

In the traditional method, students are central when improving/optimizing their own learning strategies. Specifically, in the students' own views, to improve learning strategies, students have to read textbooks and take notes about the main ideas/ confusing information before classes and then ask about or answer questions.

Findings illustrated the idea that lecturers were they key to stimulating student learning; they had to develop their pedagogical skills and create attractive content: Use brief systematic slide presentations, emphasize the main ideas, add more videos/images; update additional out-of-textbook knowledge, provide guidance on how to apply knowledge to clinical practice. Furthermore, encouraging students to participate in the lesson, but also respond to quizzes, added incentives to achieve more marks, engage with group discussions; enhancing interactions between 
lecturers and students. Summarizing the main idea at the end of each part/end of the lessons and giving evaluation questions were also suggested. Last but not least, students noted the importance of creating a favorable learning environment, for example by reducing the number of students in one class also added to the optimizing learning and teaching strategies.

"Lecturers should encourage students to participate in the class by plus mark; or after each lesson, the lecturer should give the short evaluation questions to build up student's knowledge",

"In my opinion, lecturers should enhance the interaction between lecturers and students, it means that they should not stand / sit in one place; should go up and down; give questions; commend when students answer correctly; the knowledge should be systematized at the end of lessons",

"I think the class should be reduced the number of students, provide spacious and airy classrooms, because when sitting in the crowd class causing heat, difficulty concentrating and easily chatting".

Data showed that in the PBL method, students perceived the need to be proactive, actively participate in learning activities and take responsibility for participating in group work and also remain sympathetic to different points of view and "... complete the assigned work".

There may be a range of reasons for findings that revealed impressions of how students perceive elements within the lecturer category: It was suggested lecturers should:

First, suggest important content if the student cannot comprehend; contribute ideas when students present a report. Second, work with scenarios that should be more realistic and suitable for clinical situations; add more photos/videos to make the lesson visual and attractive.

Third, increase interaction between groups, provide reliable and official references, encourage students to participate in class and gain extra marks;

Fourth, guide students through the development of some skills before undertaking PBL courses: Reference search skills, making PowerPoints and oral presentations, giving / receiving feedback, summarizing main ideas, updating new information.

The educational institution should respond to the differences in processes involved with PBL activities: "Divide students into small groups; create an enjoyable, relaxed learning atmosphere; no pressure". To achieve this, "I think teachers and the university should arrange suitable schedules: $P B L$ courses need a lot of time to prepare assignments and group discussions. And we should apply PBL method from Year 1, for students to adapt to the new method".

When glancing at the feedback on E-learning methods, one can readily see that students have to be active in learning, engage with the lessons uploaded to the E-learning system before class and also be active in arranging time for studying.

On the other hand, it was suggested lecturers should enhance their interactions between students through group discussion and ensure network qualities were reported by students: "Lecturers can give discussion questions to increase interaction between lecturers and students; attract more students".

Exam organization was an issue.

"... in order to ensure fairness in the test, it is advisable to conduct the test at the school, because when taking the test at home, the network of each students is also different, fast and slow, so some students can not take the test smoothly";

"I think the test should be conducted at school; prepare a private room, ensuring network quality for students to do the test at the same time; no exchange between students".

Student perspectives about U-learning centered on the need to actively participate in group discussion. Lecturers should download all lessons to quality learning devices and share all group presentations using the U-learning system. The addition of quality images and videos related to clinical cases and marks allocated for active students would improve learning strategies (Table 3).

\section{Discussion}

Study findings indicated advantages and limitations within students' perceptions toward different learning methods. These are discussed with reference to other studies.

Making comparisons among teaching strategies, participants saw PBL as an effective approach for achieving learning outcomes; PBL encouraged proactivity, convenience, and creativity. Visual content enhanced active learning for several core skills. Clyne \& Billiar (2016) had similar findings: PBL has been effective in motivating student learning, increasing knowledge retention, and developing problem solving, communication, and teamwork skills. The findings of Rodger \& Stewart-Lord (2020) main themes were "openness to diverse viewpoints", "developing non-technical skills" and "encouraging deep learning”. In AlKloub et al. (2014) study, participants reported effectiveness through PBL in developing cognitive abilities, independent learning, motivation to learn, and group learning.

There were perceptions of disadvantage in use of PBL methods. Limitations in learning processes included: Students take a lot of time to complete group assignments; uncertainty about information on the Internet; limits on amount of knowledge acquired when the focus is on group processes. Al-Kloub et al. (2014) had similar findings, PBL is time-consuming, has unclear objectives, is a stressful process, and results in an increased workload. E-learning has some limitations: Fairness in examinations; 
some students like the $30 \%$ described by Eldeeb (2014), have difficulties related to internet and Wi-fi quality.

Using Newble and Entwistle's model guidelines (1986), these study findings show that different teaching strategies impact differently on student's learning regarding surface, deep and strategic approaches. Teaching strategies impact different learning styles in the short and long term. Learning outcomes including improving self-motivation, good academic achievement affect student's life-long learning and careers. In the study of Bhalli et al. (2015), findings showed that instructional strategies accommodating learning styles enhanced academic performance. Previous studies point to significant relationships between the two (McKenna et al. 2018; Shirazi \& Heidari, 2019), teachers' professional satisfaction and support for ongoing professional nurse training (Vizeshfar, F., \& Torabizadeh, C. 2018). Ford et al. (2016) findings demonstrated that individual learning styles and teaching strategy had impacted quality improvement processes for teachers and practice-based learning. Dolmans et al. (2016), showed PBL enhanced active learning and students' intrinsic motivation for improve deep learning but acknowledged high perceived workloads through assessment aiming for enhancing surface learning. Sajadi et al. (2017) recognized use of learning contracts in clinical settings was indicative of greater self-directed learning among nursing students.

Given the discussion above, it is clear that selecting appropriate teaching strategies was seen as important for effective learning outcomes in the short and long term. In this study, participants' suggestions for instructional strategies for promoting student learning outcomes regarding the context of student, instructors and educational institution. Although different teaching strategies were provided, participants commented that improvements to learning were needed aiming for more up-to-date reality-based and attractive learning events, not those based on information available in books. Participants' experiences demonstrated that interest in learning was one factor that increased academic engagement, increased appeal towards subjects or educational content. Ghasemi et al. (2018) study, showed that interest in, and intellectual and mental concentration on educational subjects, increased learning efforts, and ultimately contributed to greater and deeper learning. According to Joshi et al. (2017), participants' suggestions to achieve high learning performance referred to consideration of learning styles and strategies like daily revision of topics, being regular and attentive during ward postings.

Activities offered in a lively atmosphere with interactions between students and teachers contribute to improving learning efficiency. Gablinske (2014) reported that teacher interaction behaviors refer to specific actions that allow for positive communi- cation between the teacher and students; various components of interactions have a direct impact on the instruction and learning that occurs at every moment of learning engagement. Dinkevich \& Ozuah (2003) indicated that

those participating in a problem-solving skills workshop showed significantly higher self-directed learning levels than their counterparts. Skedsmo \& Huber (2018) reported that to evaluate teachers' influence on their students' improvement learning achievement, one needs to consider the approach or model adopted for the assignments.

The participants in this study suggested that subjects should be spread throughout the semester, not focusing on multiple subjects at a time to avoid a decrease in academic quality. Joshi et al. (2017) study found that in unstructured timetable, lack of planning was identified in student's low performance. Thus if participants were given reasonable learning schedules, with suitable clinical practice time, effective gains in learning were achieved. In relation to student's knowledge acquisition, a study by Kashif \& Basharat, (2014) showed that the class size and its relationship to student engagement in classrooms could not be neglected; students lacked a spirit of 'engagement' in large classes.

\section{CONCLUSION}

The findings of this study provide insight into students' perspectives on advantages and disadvantages of offering different educational strategies, and the influence of these on their approach to learning. Suggestions for instructional strategies and enhancing learning outcomes need to be seen in the context of student, instructor and systems. Further studies focusing on applying the findings to ways to improve academic engagement are recommended.

Given that nearly a decade ago, MOET suggested that the teaching methods in higher education in Vietnam were not effective because the focus was not on encouraging students to be more active in learning events, we also need to ask "To what extent have we achieved the goals set for students involved in higher education?

\section{Acknowledgements}

This paper was supported by funding from the Halla Newcastle PBL Education and Research Center. We would like to express our sincere thanks to Prof. Margaret McMillan for her valuable suggestion and edition. 


\section{REFERENCES}

Al-Kloub, M. I., Salameh, T. N., \& Froelicher, E. S. (2014). Nursing students evaluation of problem based learning and the impact of culture on the learning process and outcomes: A pilot project. Nurse Education in Practice, 14(2), 142-147.

Bhalli, M. A., Khan, I. A., \& Sattar, A. (2015). Learning style of medical studentsand its correlation with preferred teaching methodologiesand academic achievement. Journal of Ayub Medical College, Abbottabad: JAMC, 27(4), 837-842.

Clyne, A. M., \& Billiar, K. L. (2016). Problem-based learning in biomechanics: advantages, challenges, and implementation strategies. Journal of Biomechanical Engineering, 138(7).

Devine, T. G., \& Meagher, L. D. (1989). Mastering study skills: A student guide. New Jersey: Prentice Hall.

Dinkevich, E., \& Ozuah, P. O. (2003). Self-directed learning activities of paediatric residents. Medical Education, 37(4), 388-389.

Dolmans, D. H. J. M., Loyens, S. M. M., Marcq, H., \& Gijbels, D. (2016). Deep and surface learning in problem-based learning: A review of the literature. Advances in Health Sciences Education, 21(5), 1087-1112.

Eldeeb, R. (2014). Students' perceptions to e-learning. IOSR Journal of Research \& Method in Education (IOSRJRME), 4(3), 33-36.

Ford, J. H., Robinson, J. M., \& Wise, M. E. (2016). Adaptation of the grasha riechman student learning style survey and teaching style inventory to assess individual teaching and learning styles in a quality improvement collaborative. BMC Medical Education, 16(1), 252.

Gablinske, P.B. (2014). A case study of student and teacher relationships and the effect on student learning. Open Access Dissertations, University of Rhode Island, Kingston, USA. https:// digitalcommons.uri.edu/oa_diss/266

Ghasemi, M. R., Moonaghi, H. K., \& Heydari, A. (2018). Student-related factors affecting academic engagement: A qualitative study exploring the experiences of Iranian undergraduate nursing students. Electronic Physician, 10(7), 7078-7085.

Heath, M., Ellen, S., \& Kaira, H. (2009). Study strategy predictors of performance in introductory psychology. The Free Library. Retrieved November 18, 2009, from http://www.thefreelibrary. com/Study strategy predictors of performance in introductory psychology-a0204682053

Joshi, A. S., Ganjiwale, J. D., Varma, J., Singh, P., Modi, J. N., \& Singh, T. (2017). Qualitative assessment of learning strategies among medical students using focus group discussions and indepth interviews. International Journal of Applied \& Basic Medical Research, 7(Suppl 1), S33-S37.
Kashif, M., \& Basharat, S. (2014). Factors impacting university students' engagement with classroom activities: Qualitative study. International Journal of Management in Education, 8(3), 209-224.

Marzano, R. J., Pickering, D. J., \& Pollock, J. E. (2001). Classroom instructions that work: Research based strategy for increasing studentsachievement. Alexandria, VA. Association for Supervision of Curriculum Development.

Mayer, R. (1988). Learning strategies: An overview. In Weinstein, C., E. Goetz, \& P. Alexander (Eds.), Learning and Study Strategies: Issues in Assessment, Instruction, and Evaluation (pp. 1122).New York: Academic Press.

McKenna, L., Copnell, B., Butler, A. E., \& Lau, R. (2018). Learning style preferences of Australian accelerated postgraduate pre-registration nursing students: A cross-sectional survey. Nurse Education in Practice, 28, 280-284.

Newble, D. I., \& Entwistle, N. J. (1986). Learning styles and approaches: Implications for medical education. Medical Education, 20(3), 162-175.

Ngo, T. (2010). It should re-innovate of teaching method in university. Retrieved December 3, 2010 from: http://www.dantri. com.vn.

Nguyen, T. A. P., Mai, B. H., Nguyen, V. Q.H., \& Cao, N. T. (2017). Innovation of teaching methodology in health education: The first application of active teaching in nursing education at Hue University of Medicine and Pharmacy. Reported in: "Workshop of innovation and creation in learning and teaching".

Rodger, D., \& Stewart-Lord, A. (2020). Students' perceptions of debating as a learning strategy: A qualitative study. Nurse Education in Practice, 42, 102681.

Sajadi, M., Fayazi, N., Fournier, A., \& Abedi, A. R. (2017). The impact of the learning contract on self-directed learning and satisfaction in nursing students in a clinical setting. Medical Journal of the Islamic Republic of Iran, 31, 72.

Shirazi, F., \& Heidari, S. (2019). The Relationship between critical thinking skills and learning styles and academic achievement of nursing students. The Journal of Nursing Research: JNR, 27(4), e38.

Skedsmo, G., \& Huber, S. G. (2018). Reliability, validity and fairness-Key issues in assessing the quality of teaching, instructional leadership and school practice. Educational Assessment, Evaluation and Accountability, 30(4), 343-346.

Temmerman, N. (2019). Transforming higher education in Vietnam.University World News. https://www.universityworldnews.com/post.php?story $=20190129142655883$.

Tran, D. H., Mai, B. H., \& Nguyen, T. M. T., (2017). Applying problem based learning in nursing education for basic nursing 
subjects at Hue University of Medicine and Pharmacy. Hue University of Medicine and Pharmacy Conference in Creation Working.

Vietnamese Communist Party (2013). Documents of the 8th national conference of central committee of Communist party, Na- tional politics publishing house, Hanoi.

Vizeshfar, F., \& Torabizadeh, C. (2018). The effect of teaching based on dominant learning style on nursing students' academic achievement. Nurse Education in Practice, 28, 103-108. 